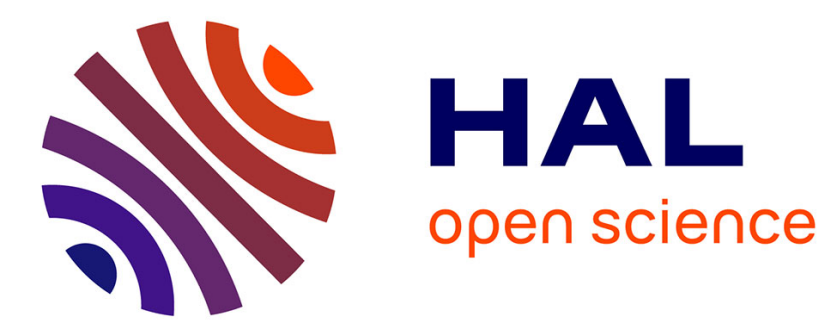

\title{
Use of Wehner Schulze to predict skid resistance of Irish surfacing materials
}

\author{
Shaun Friel, Malal Kane, David Woodward
}

\section{To cite this version:}

Shaun Friel, Malal Kane, David Woodward. Use of Wehner Schulze to predict skid resistance of Irish surfacing materials. 2013 Airfield and Highway Pavement, Jun 2013, France. 12 p. hal-00851551

\section{HAL Id: hal-00851551 \\ https://hal.science/hal-00851551}

Submitted on 14 Aug 2013

HAL is a multi-disciplinary open access archive for the deposit and dissemination of scientific research documents, whether they are published or not. The documents may come from teaching and research institutions in France or abroad, or from public or private research centers.
L'archive ouverte pluridisciplinaire HAL, est destinée au dépôt et à la diffusion de documents scientifiques de niveau recherche, publiés ou non, émanant des établissements d'enseignement et de recherche français ou étrangers, des laboratoires publics ou privés. 


\title{
Use of Wehner Schulze to predict skid resistance of Irish surfacing materials
}

\author{
Shaun Friel ${ }^{1}$, Malal Kane ${ }^{2}$ and David Woodward ${ }^{3}$ \\ ${ }^{1}$ University of Ulster, School of the Built Environment, Newtownabbey, Co. Antrim, \\ Northern Ireland; email friel-s3@email.ulster.ac.uk \\ 2 IFSTTAR, Nantes, France; email malal.kane@ifsttar.fr \\ ${ }^{3}$ University of Ulster, School of the Built Environment, Newtownabbey, Co. Antrim, \\ Northern Ireland; email wdh.woodward@ulster.ac.uk
}

\begin{abstract}
This paper details the first assessment of asphalt mixes used in Ireland using the Wehner Schulze test equipment. The mixes assessed were 10mm SMA, 14mm SMA and hot rolled asphalt (HRA) made with PSV 62 greywacke aggregate. The Wehner Schulze was developed about 30 years ago in Germany and is currently being considered as a European Standard test method. The equipment used was located at IFSTTAR in Nantes, France. Asphalt test specimens $(305 \mathrm{~mm}$ x $305 \mathrm{~mm}$ x $50 \mathrm{~mm}$ ) were prepared using a Cooper roller compactor. $225 \mathrm{~mm}$ diameter cores were then extracted from the slabs for testing on the WS machine. The results found the $10 \mathrm{~mm}$ and $14 \mathrm{~mm}$ to have higher friction coefficient values compared to the hot rolled asphalt. Analysis of the data suggests that this is probably due to differing types of contact between the asphalt surface and the Wehner Schulze polishing rollers and rubber pads used for friction measurement. The investigation suggests that the tire / asphalt surface interface needs further research to help explain both the laboratory and on-site measurement of friction.
\end{abstract}

\section{INTRODUCTION}

Throughout Europe, the specification of aggregate for use in asphalt surface mixes is based on polished stone value (PSV) test. A problem with PSV test is that only assesses the $10 / 6.3 \mathrm{~mm}$ aggregate size. Laboratory and in-service research studies has found that the standard PSV test may not reflect what is actually happening in a real highway surface (Woodward, 1995; Perry, 1996; Roe and Hartstone, 1998). Testing regimes should be adopted that adequately predict a materials performance against conditions that will be encountered in a real highway surface i.e. there is a need to better understand and predict the polishing resistance of the combined components of asphalt mixes and how they interact with vehicle tyres. 


\section{METHODS TO PREDICT ASPHALT MIX SKID RESISTANCE OF}

There have been different attempts to improve on the PSV method and assess asphalt mixes. For example, the Penn State Reciprocating Polishing Machine (Nitta et al., 1990), the North Carolina State Wear and Polishing Machine and the Michigan Wear Track (McDaniel and Coree, 2003) are devices developed to simulate polishing of aggregate or asphalt mixtures. The National Centre for Asphalt Technology (NCAT) developed a test apparatus which uses three pneumatic tyres to polish a $24 \mathrm{x}$ 24 inch asphalt slab. Friction is assessed using the Dynamic Friction Tester (Vollor and Hanson, 2006). Wilson and Dunn (2005) developed the NCAT apparatus at the University of Auckland, making modifications to better control wheel loads as well as taking account of higher macrotexture and surface irregularities of chip seal surfaces.

The Road Test Machine (RTM) at University of Ulster is used to research the polishing and wear characteristics of asphalt surfacing materials (Friel et al., 2010; Friel et al., 2011a; Friel et al., 2011b). It is also used to assess the wear characteristics of High Friction Surfacing systems for BBA accreditation for use in the United Kingdom in accordance with Appendix H of TRL Report 176 (Nicholls, 1997). The RTM consists of a $2.1 \mathrm{~m}$ diameter table that rotates at $10 \mathrm{rpm}$. Up to ten $305 \mathrm{~mm} \times 305 \mathrm{~mm} \times 50 \mathrm{~mm}$ asphalt test specimens can be mounted on this table.

Two vertically mounted real-size tyres run freely on the table, applying a load of approximately $5 \mathrm{kN}$, and simulating real trafficking/polishing. During testing, the tyres track back and forth across the width of the test specimen generating extra stressing on the specimens. The RTM is enclosed in a temperature controlled room where testing is carried out at $10+/-2^{0} \mathrm{C}$. Both the number of rotations and temperature are recorded automatically. The RTM can be programmed to stop after a specified number of rotations. The RTM is not capable of direct friction measurement, therefore, measurements are taken using the pendulum tester.

The Wehner Schulze (WS) test was developed in the 1960s by Professors Wehner and Schulze at the Technical University of Berlin (TUB) as an alternative to the PSV test. During the 1990s the test method underwent further development that produced what is now known as the WS machine. The WS, shown in Figure 1, is an integrated machine consisting of two rotary heads, one for polishing of specimens and one for friction measurement of specimens. The specimens for testing on the WS machine are usually $225 \mathrm{~mm}$ cores. The specimens can be either mosaics of aggregate only or asphalt cores either obtained from an actual highway surface or manufactured in the laboratory.

The polishing process is carried out by three rubber conical rollers (Figure 2a) rotating at $500 \mathrm{rpm}$, giving a linear speed of $17 \mathrm{~km} / \mathrm{h}$, with the contact pressure being $0.4 \mathrm{~N} / \mathrm{mm}^{2}$. One rotation of the rotary head equals three roller passes. There is a slip between the cone and specimen surface between $0.5 \%$ and $1 \%$. During testing a water-abrasive mix is projected on the specimen surface (Woodbridge et al., 2006; 
Do et al., 2009). The friction measurement process is carried out by three small rubber slider pads $(30 \mathrm{~mm} \times 14.5 \mathrm{~mm})$ attached to a rotating head (Figure $2 \mathrm{~b}$ ). The measuring head is rotated to a speed of $2700 \mathrm{rpm}(90 \mathrm{~km} / \mathrm{h})$ at which point water is projected on to the specimen to give a theoretical water film thickness of $0.5 \mathrm{~mm}$. When the rotating head reaches $3000 \mathrm{rpm}(100 \mathrm{~km} / \mathrm{h})$ the motor is turned off and the head drops until making contact with the specimen surface, the contact pressure being $0.2 \mathrm{~N} / \mathrm{mm}^{2}$. The rotating head and rubber slider pads decelerate when making contact with the specimen and the measured frictional forces are recorded by a computer which calculates the coefficient of friction (Woodbridge et al., 2006; Do et al., 2009).

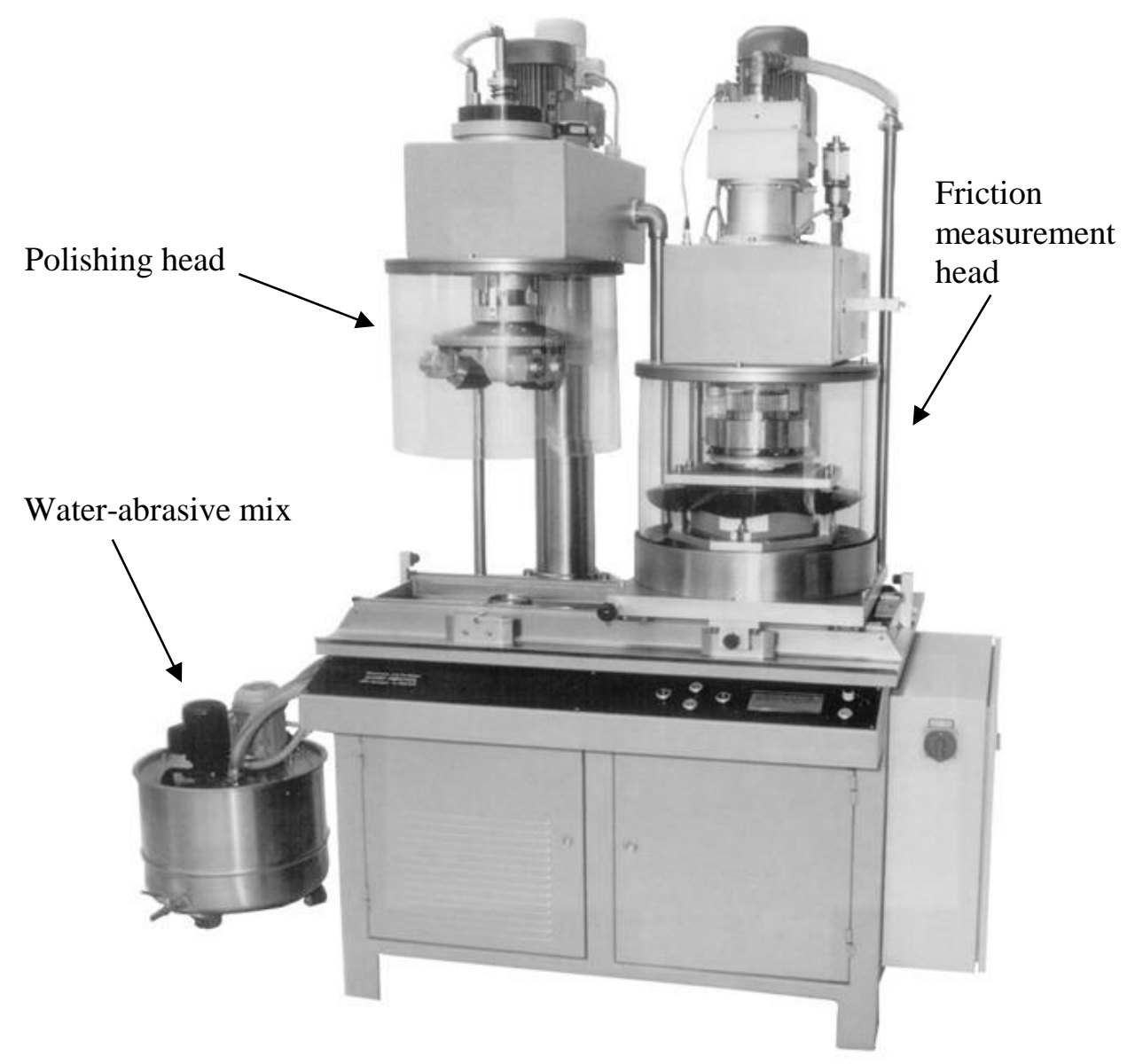

Figure 1. The Wehner Schulze machine 


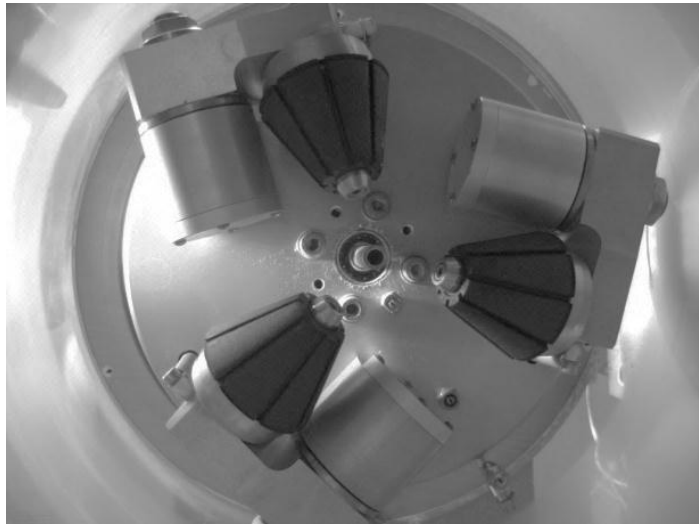

(a)

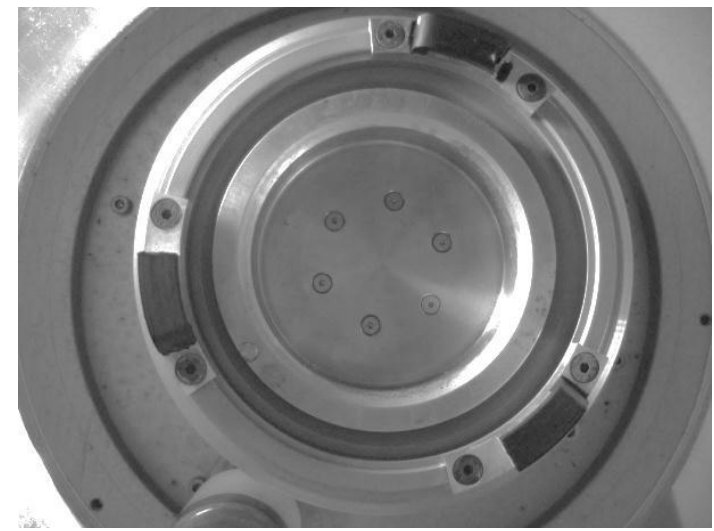

(b)

Figure 2. (a) Three rubber conical polishing rollers; (b) Three rubber slider pads

\section{REVIEW OF PREVIOUS WEHNER SCHULZE USE}

The WS test is currently being considered as a European Standard test method as a potential alternative or replacement for the PSV test. Different studies have been undertaken throughout Europe to assess the WS test. As each country may use differing asphalt mixes across their respective highway networks, it is important that the WS test (or any potential test method) be able to adequately assess a specific country's range of asphalt mixes. This means that the WS test, if it is to be considered as a European Standard test method, must be able to adequately assess a varied menu of differing asphalt mix types.

Do et al. (2007) undertook a study to assess whether the WS test could forecast the evolution of skid resistance. This involved extracting core specimens from three highway surfaces. The materials extracted were $10 \mathrm{~mm}$ asphalt concrete (AC), $10 \mathrm{~mm}$ very thin asphalt concrete (VTAC), and 6mm VTAC. These are widely used on French main and secondary roads. The type and PSV of the aggregates used in each of the mixes is given in Table 2 .

Table 2. Asphalt mix, aggregate type and PSV (Do et. al. 2009)

\begin{tabular}{|l|l|l|}
\hline Asphalt mix & Aggregate type & PSV \\
\hline 10mm AC & Spilite & 53 \\
\hline $10 \mathrm{~mm}$ VTAC & Gabbro & 51 \\
\hline $6 \mathrm{~mm}$ VTAC & Rhyolite & 55 \\
\hline
\end{tabular}

The cores were assessed using the WS test. The friction evolution curves are shown in Figure 3. This shows an initial increase in friction after initial polishing to a maximum value, followed by a decrease in friction. Cores were extracted from the sites for 2 years and the data compared. The authors found that the site data and laboratory data showed good early agreement. However, this work is continuing and further assessment of site data is required annually to validate the laboratory work. 


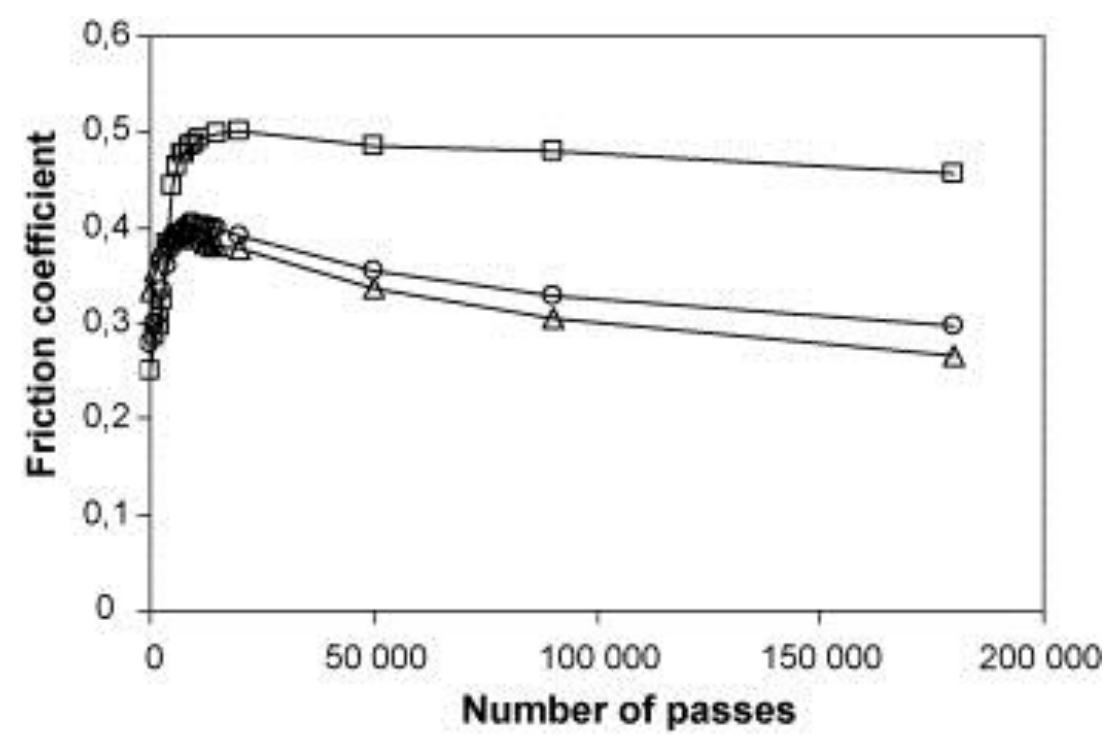

$\square-V T A C 0 / 6-0-V T A C 0 / 10 \triangle \triangle A C$ O/10

Figure 3. WS friction evolution curves (Do et al., 2007)

Allen et al. (2008) considered the PSV and WS test methods for a range of UK asphalt mix and aggregate types. Eleven types of asphalt mix were assessed with the majority of the mixes being proprietary asphalt surfacing mixes. The mixes contained aggregates having a range of PSV from 55 to 70 . Figure 4 shows the friction evolution curves for the materials assessed.

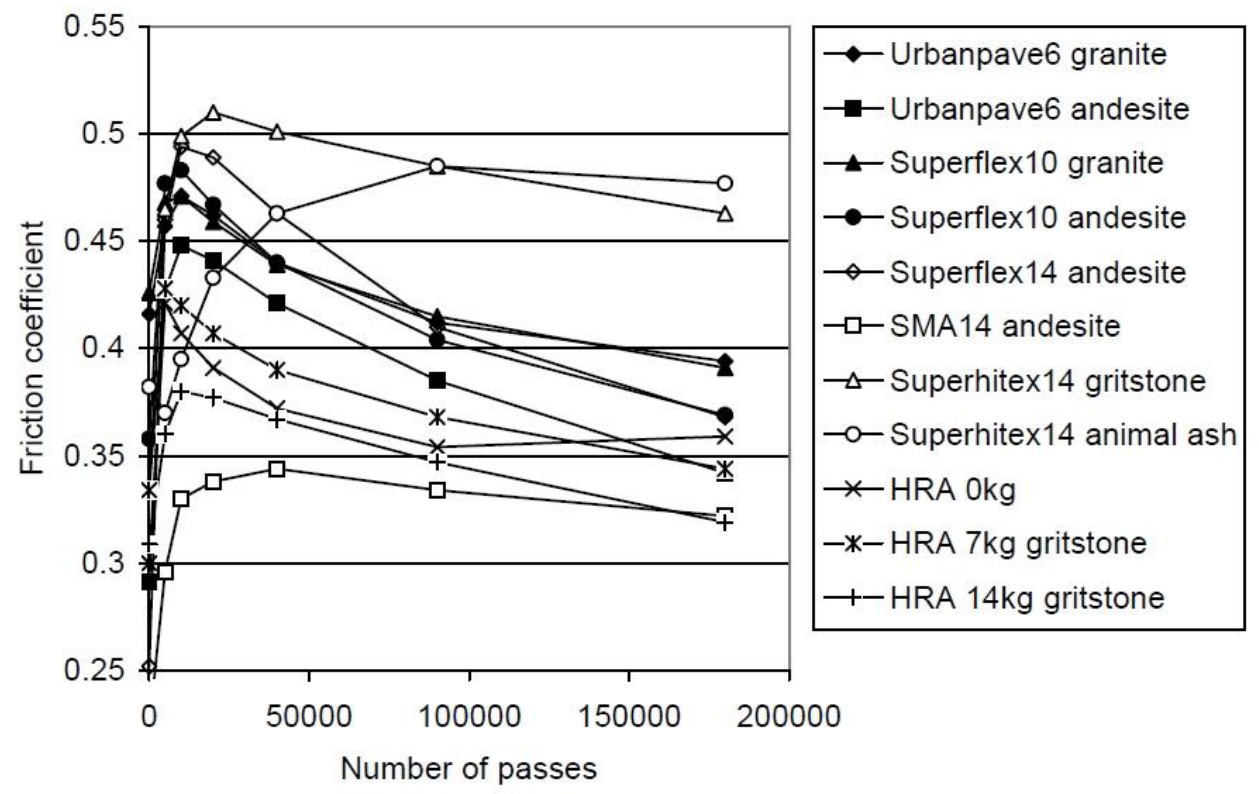

Figure 4. WS friction evolution curves (Allen et al., 2008) 
Allen et. al. (2008) found that granite mixes made with PSV 55 aggregate outperformed similar andesite mixes made with PSV 60 aggregate. HRA mixes performed poorly with increasing the quantity of $20 \mathrm{~mm}$ pre-coated chippings resulting in a lowering of WS friction coefficient. Maximum friction coefficients were found to occur at approximately 20,000 cycles, with equilibrium conditions not achieved after 180,000 cycles. There was no meaningful correlation found between WS of the asphalt mixes and PSV of the aggregate used in the mixes assessed. PSV 55 granite used in $6 \mathrm{~mm}$ and $10 \mathrm{~mm}$ nominal size mixes outperformed PSV 65 gritstone used as pre-coated $20 \mathrm{~mm}$ chippings applied to HRA.

\section{ASPHALT ASSESSED IN THIS INVESTIGATION}

The asphalt mixes were 10mm SMA, 14mm SMA and a 35/14 Hot Rolled Asphalt (HRA). The aggregate used in all of the mixes was Silurian greywacke with PSV 62. These were sampled during production at an asphalt plant in Ireland. Table 1 summarises the aggregate grading and bitumen content of each asphalt mix. The sampled asphalt was reheated and slabs $305 \times 305 \times 50 \mathrm{~mm}$ in size prepared using a Cooper roller compactor. The HRA test specimens had $20 \mathrm{~mm}$ pre-coated chippings rolled unto their surface to give texture. Three test specimens were prepared for each asphalt. The slabs were shipped to the IFSTTAR laboratory in Nantes, France. A $225 \mathrm{~mm}$ diameter core was extracted from each slab for WS testing.

Table 1. Composition of the asphalt materials used in the investigation

\begin{tabular}{|l|c|c|c|}
\hline \multirow{2}{*}{ Sieve size $(\mathrm{mm})$} & \multicolumn{3}{|c|}{ Percentage passing $(\%)$} \\
\cline { 2 - 4 } & $14 \mathrm{~mm}$ SMA & $10 \mathrm{~mm}$ SMA & $35 / 14$ HRA \\
\hline 20 & 100 & - & 100 \\
\hline 14 & 97 & 100 & 97 \\
\hline 10 & 51 & 99 & 77 \\
\hline 8 & 39 & 74 & 68 \\
\hline 6.3 & 34 & 44 & 67 \\
\hline 4 & 31 & 35 & 66 \\
\hline 2 & 22 & 26 & 65 \\
\hline 1 & 17 & 18 & 63 \\
\hline 0.500 & 15 & 15 & 59 \\
\hline 0.250 & 12 & 12 & 44 \\
\hline 0.125 & 10 & 10 & 15 \\
\hline 0.063 & 7.6 & 7.7 & 7.4 \\
\hline Binder content & 6.0 & 6.2 & 7.3 \\
\hline
\end{tabular}

\section{WEHHNER SCHULZE TESTING}

Each test specimen was subjected to polishing and friction measurement using the Wehner Schulze machine. A total of 180,000 polishing cycles was used. Testing was repeatedly stopped and friction measured. Figure 5 plots the evolution of 
friction coefficient for all nine test specimens with increasing number of WS polishing cycles. Figure 6 plots average friction coefficient for each asphalt type up to 180,000 polishing cycles. Figure 7 plots data for the first 30,000 polishing cycles to observe their early life development.

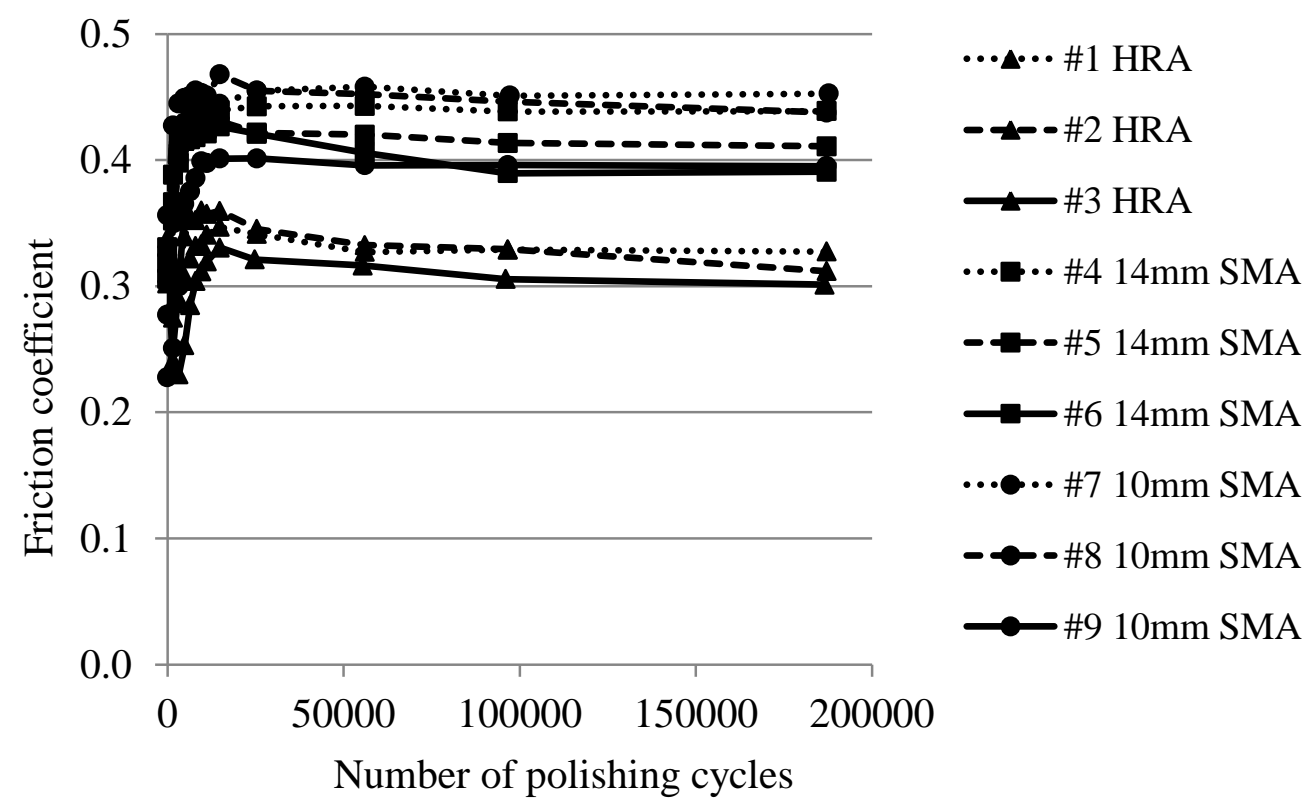

Figure 5. Evolution of friction coefficient - all data

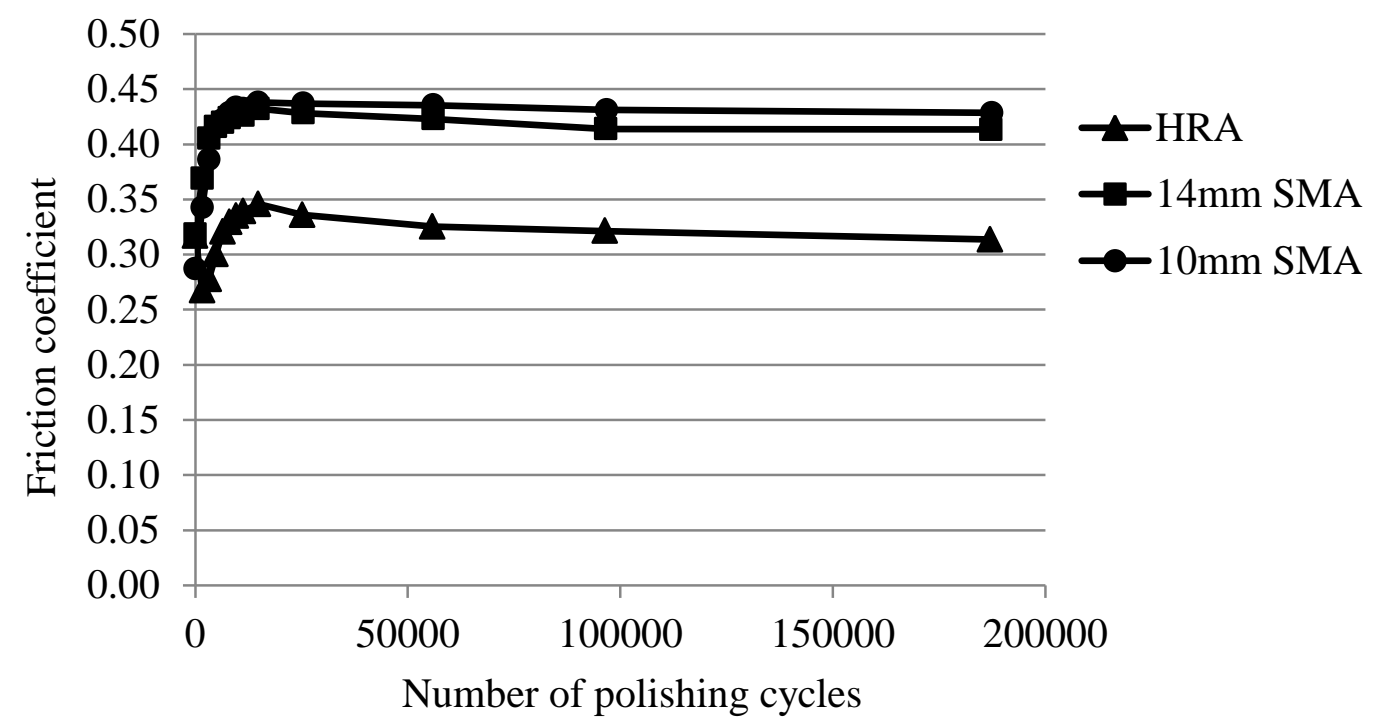

Figure 6. Evolution of friction coefficient - averaged data 


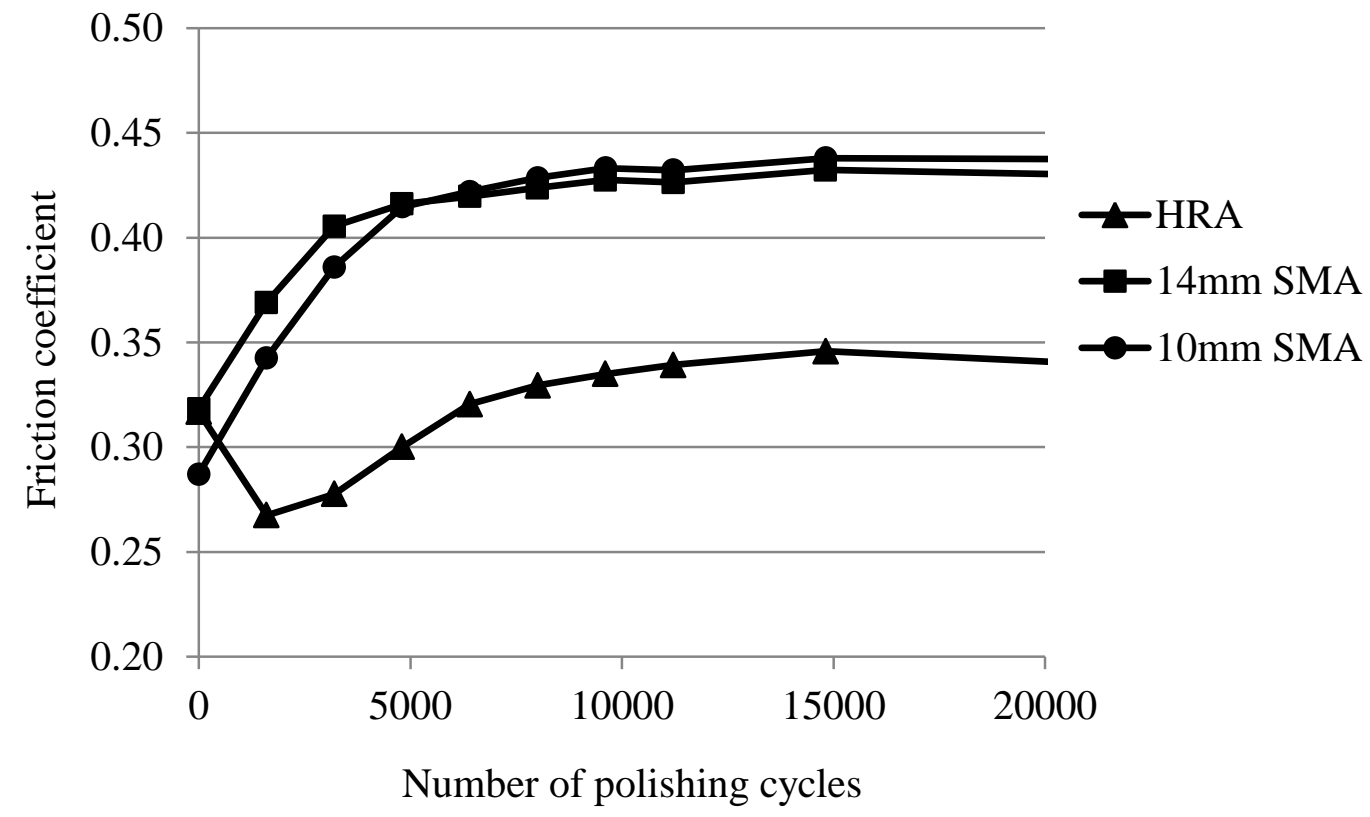

Figure 7. Evolution of friction coefficient - early life

Figures 8 and 9 show images of HRA and 14mm SMA test specimens respectively, before and after 180,000 polishing cycles. This shows the different surface textures of the 2 asphalt mix types.

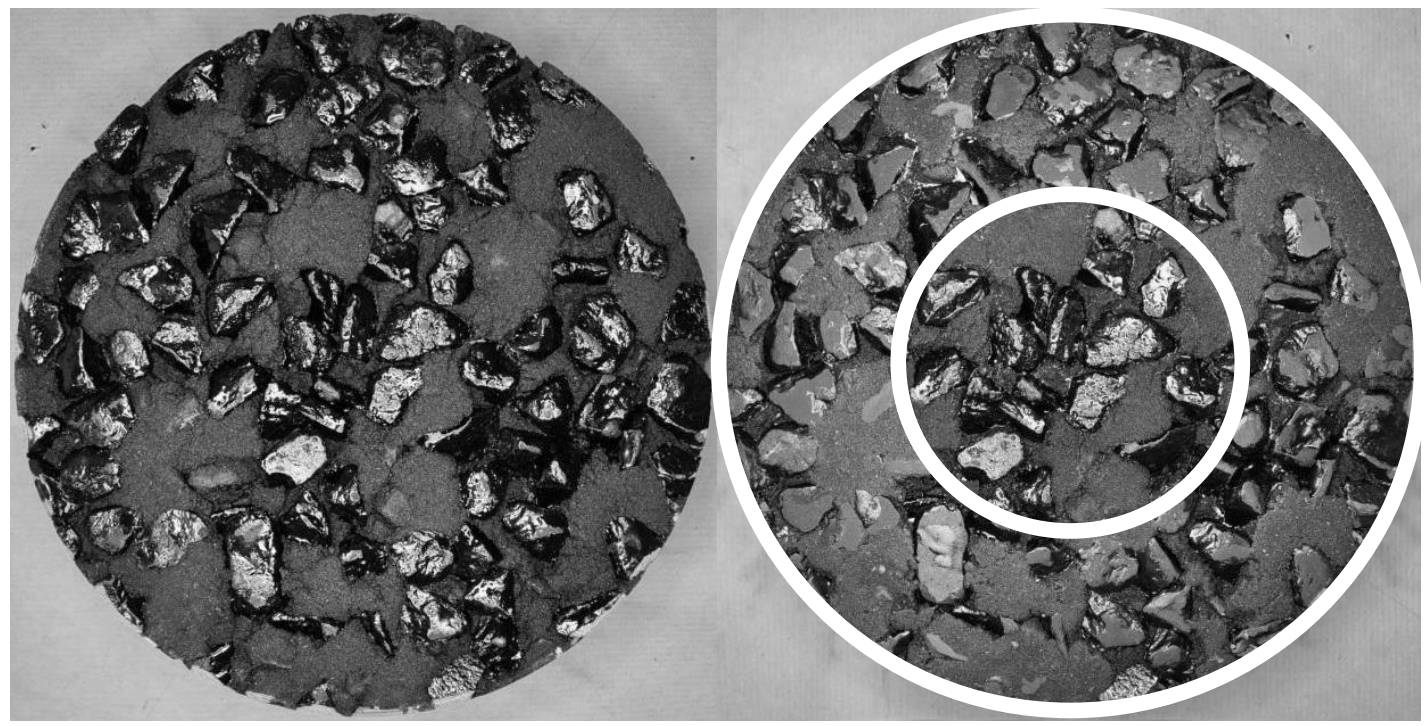

(a)

(b)

Figure 8. (a) HRA before polishing; (b) HRA after polishing 


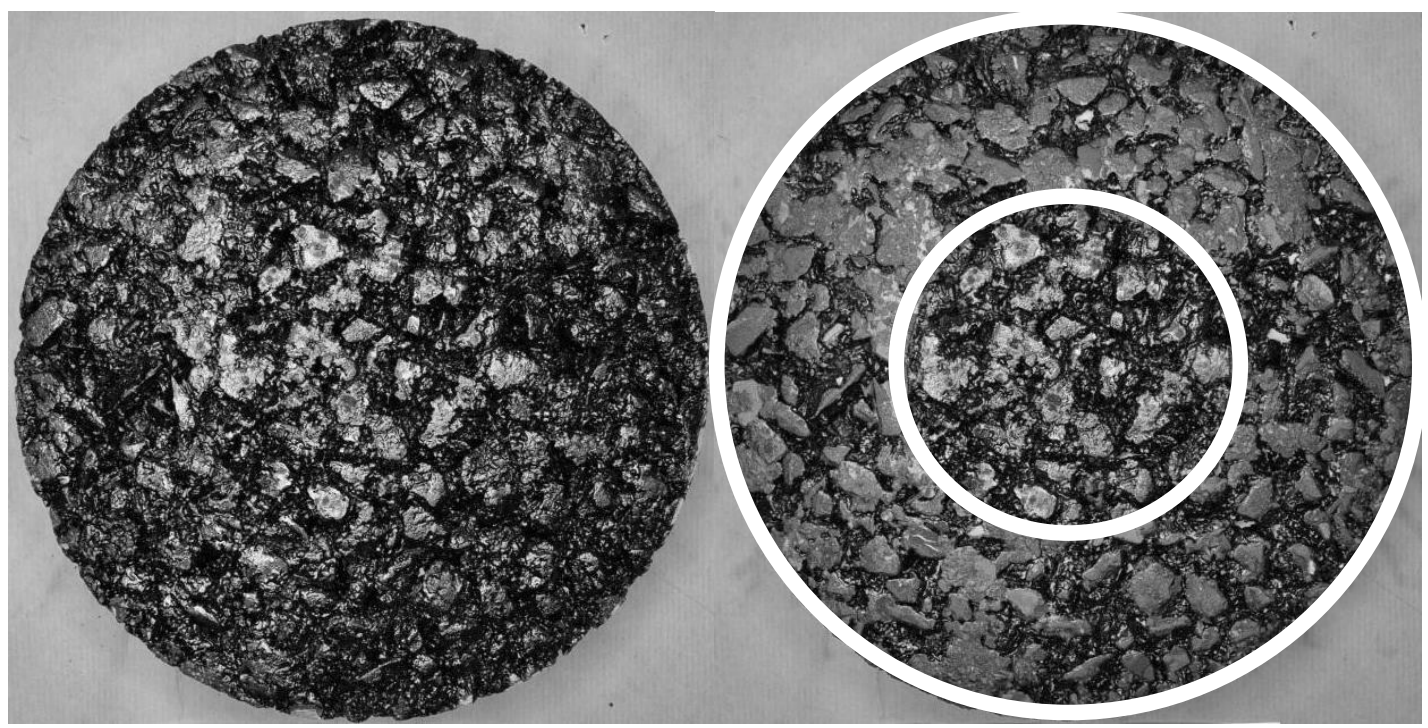

(a)

(b)

Figure 9. (a) 14mm SMA before polishing; (b) 14mm SMA after polishing

\section{DISCUSSION}

The found data follows the same general trends to that found in previous studies. Figure 5 plots the evolution of friction coefficient for all nine test specimens with increasing number of WS polishing cycles. This shows friction coefficient to range from 0.3 to 0.45 after 180,000 cycles for all 9 test specimens / 3 asphalt mix types. This shows that the WS equipment is predicting that different friction coefficients are possible for the same aggregate if used in different types of asphalt mix.

This questions the philosophy of a specification for aggregate skid resistance based on PSV. It raises issues ranging from over specifying / underspecifying to not optimising the potential of an aggregate source. Testing the asphalt mix rather than simply the $10 / 6 \mathrm{~mm}$ size suggests that wet skid resistance for an aggregate can be optimised depending on what type of asphalt mix it is used.

Figure 6 plots average friction coefficient up to 180,000 polishing cycles. The $10 \mathrm{~mm}$ SMA has the highest average friction coefficient followed closely by the $14 \mathrm{~mm}$ SMA. The HRA is significantly lower. Maximum friction coefficient occurred at approximately 15,000 polishing cycles for the three mixes. Continued polishing cycles did not cause this value of friction co-efficient to significantly decrease i.e. after reaching maximum friction coefficient the asphalt mixes assessed would appear to be at equilibrium. Continued polishing did not cause further reduction in friction coefficient.

Figure 7 plots data for the first 30,000 polishing cycles to observe their early life. The $10 \mathrm{~mm}$ and $14 \mathrm{~mm}$ SMA both followed similar trends with their friction 
coefficient increasing to a maximum value at approximately 15,000 polishing cycles. The HRA data shows an initial decrease followed by an increase to maximum friction coefficient at approximately 15,000 polishing cycles. The increase in SMA friction coefficient to a maximum at approximately 15,000 cycles may be explained by steady removal or stripping of the binder/mastic component surrounding the coarse aggregate in contact with the WS polishing rollers. After the maximum coefficient of friction is reached, the majority of aggregate is exposed and has been polished to equilibrium.

The initial decrease in friction coefficient for the HRA is more difficult to explain. It is probably related to a smaller contact area for the $20 \mathrm{~mm}$ chippings and WS polishing rollers / rubber slider pads. The low pen grade bitumen surrounding the pre-coated chipping may go through a short period of initial polishing i.e. the early life drop. The bitumen then starts to wear off exposing the micro-texture of the aggregate. Friction coefficient is less, probably reflecting the lower available contact area of the $20 \mathrm{~mm}$ chippings. Maximum friction coefficient is reach at approximately 15,000 polishing cycles. This would also appear to be equilibrium. The role of the HRA mastic component is less certain in the evolution of friction coefficient.

Figures 8 and 9 show before and after polishing examples for HRA and $14 \mathrm{~mm}$ SMA respectively. The two asphalt mixes have different surface textures and contact areas. This suggests different roller / rubber slider contact mechanisms for the asphalt mixes. The similarity between the $10 \mathrm{~mm}$ and $14 \mathrm{~mm}$ SMA data may be explained by them having similar type of surface texture contact. The HRA surface texture contact is visually different and accounts for the lower friction coefficient measured.

The polished images show that the WS rollers do not drape down around the aggregate particles as would be expected for real life trafficked asphalt i.e. the polishing head load is not evenly distributed but concentrated for asphalt mixes with less contact area. For the asphalt mixes assessed, a similar level of friction coefficient for the two SMA mixes reflects their similar contact area. The lower friction coefficient for the HRA may be caused by greater loading of the smaller contact area during polishing.

\section{CONCLUSIONS}

This paper discusses the first Wehner Schulze assessment of asphalt mixes used in Ireland. Testing was carried out at the IFSTTAR laboratory in Nantes, France. Three types of surfacing asphalt were assessed i.e. 10mm SMA, 14mm SMA and hot rolled asphalt (HRA) with $20 \mathrm{~mm}$ pre-coated chippings. The same PSV 62 greywacke aggregate was used in all mixes. The test specimens were subjected to 180,000 polishing cycles and the evolution of friction co-efficient measured at regular intervals. 
The 10mm SMA was found to have the highest WS friction coefficient closely followed by the $14 \mathrm{~mm}$ SMA. The HRA was significantly lower. This shows that the WS equipment is predicting that different friction coefficients are possible for the same aggregate if used in different types of asphalt mix. Testing the asphalt mix rather than simply the $10 / 6 \mathrm{~mm}$ size suggests that wet skid resistance for an aggregate can be better optimised. This offers hope for those aggregates that do not have the higher levels of PSV but may perform better than expected in-service.

Maximum friction coefficient occurred at approximately 15,000 polishing cycles for the three mixes. Continued polishing cycles did not cause this value of friction co-efficient to significantly decrease i.e. after reaching maximum friction coefficient the asphalt mixes assessed appear to be at equilibrium with the WS test conditions. This may be a limiting factor in predicting friction coefficient for an asphalt subjected to different trafficking conditions.

The poorer performance of the positively textured HRA indicates that the contact mechanisms between the WS polishing rollers and the rubber slider pads may have a significant influence on the development and measurement of friction coefficient.

If the Wehner Schulze test is to be adapted as a European Standard test method, it must be able to realistically assess a varied menu of differing asphalt mix types. This paper suggests that more research is required to better understand its ability and operating limitations.

\section{REFERENCES}

Allen, B., Phillips, P., Woodward, D. and Woodside, A., 2008. Prediction of UK surfacing skid resistance using Wehner Schulze and PSV. Cheltenham, England, International Conference Managing Road and Runway Surfaces to improve Safety. SaferRoads.org.

Do, M.-T., Tang, Z., Kane, M. \& de Larrard, F., 2007. Pavement polishing Development of a dedicated laboratory test and its correlation with road results. Wear, Volume 263, pp. 36-42.

Friel, S., Woodward, D. and Woodside, A., 2011a. Laboratory prediction of thin surfacing early life asphalt surfacing properties. Proceedings of the 10th International Conference Sustainable Construction Materials and Technology in Asphalt, Pavement Engineering and Highways Maintenance. 16-17 February 2011.

Friel, S., Woodward, D., Woodside, A. and Doherty, G., 2011b. Predicting the Wear Characteristics of Irish Limestone AC Mixes. Thessaloniki, Greece, Proceedings of the 5th International Conference Bituminous Mixtures and Pavements, 1st 3rd June. 
Friel, S., Woodward, D., Woodside, A. and Fitzpatrick, S., 2010. Laboratory prediction of early life asphalt surfacing properties. Dublin, Ireland, Proceedings of ITRN Conference, 31st August - 1st September.

McDaniel, R. and Coree, B., 2003. Identification of laboratory techniques to optimise superpave HMA surface friction characterisation, Phase 1: Final Report SQDH 2003-6, West Lafayette, Indiana.

Nicholls, J., 1997. Laboratory tests on high friction surfaces for highways. TRL Report 176, Crowthorne: TRL Limited.

Nitta, N., Saito, K. and Isozaki, S., 1990. Evaluating the polishing properties of aggregates and bituminous pavement surfaces by means of the Penn State Reciprocating Polishing Machine. Surface Characteristics of Roadways: International Research and Technologies, ASTM STP 1031. Philadelphia, W.E Meyer and J. Reichert, Eds., American Society for Testing and Materials, pp. 113-126.

Perry, M. J., 1996. A study of the factors influencing the polishing characteristics of gritstone aggregate. DPhil Thesis, University of Ulster.

Roe, P. G. and Hartshorne, S. A., 1998. The Polished Stone Value of aggregates and in-service skidding resistance, Transport Research Laboratory, Crowthorne, U.K.

Vollor, T. and Hanson, D., 2006. Development of laboratory procedure for measuring friction of HMA mixtures - Phase 1, NCAT Report No. 06-06, Auburn, Alabama: National Centre for Asphalt Technology.

Wilson, D. and Dunn, R., 2005. Polishing aggregates to equilibrium skid resistance. Christchurch, New Zealand, First International Conference on Surface Friction, Roads and Runways, 1-4 May.

Woodbridge, M. and Dunford, A. R. P., 2006. Wehner-Schulze machine: First UK experiences with a new test for polishing resistance in aggregates. Published Project Report PPR144, Crowthorne: TRL Limited.

Woodward, D., 1995. Laboratory prediction of surfacing aggregate performance. DPhil Thesis, School of Built Environment, University of Ulster.

\section{ACKNOWLEDGEMENTS}

The research presented in this paper was funded by the National Roads Authority of Ireland through the NRA Research Fellowship Programme. The views expressed are not necessarily those of the National Roads Authority. 